advantages similar to those often accorded abstainers from alcohol. Occasional catastrophes not indicated by the usual tests might then be foreseen; healthy people with healthy habits do not die suddenly from exposure to cold or a little extra pressure of business.

Birmingham.

\section{Clinital 筧otes:}

\section{MEDICAL, SURGICAL, OBSTETRICAL, AND THERAPEUTICAL.}

\section{ANOTHER PRESUMED CASE OF ACUTE YELLOW A TROPHY OH THE LIVER.'}

By JAMES J. ANNING, L.S.A.,

ANASTHETIST TO THE HOSPITAL FOR WOMEN AND CHILDREN, LEEDS.

IN view of the rarity of this disease I report the following case which has recently been under my care.

The patient, a primipara, aged 23 years, was delivered by me on the evening of August 5th this year of a full-term hydrocephalic female child. The health during pregnancy up to labour had been quite normal. There was no albuminuria. Labour being difficult and prolonged, instrumental assistance was used and the patient was kept under moderately deep chloroform anæithesia for the space of about two hours. The perineum was partially ruptured and was repaired forthwith with silkworm-gut sutures. At the termination of delivery the pulse was noted to be feeble and rapid. The uterus contracted well and there was no undue hæmorrhage. On the following morning I found the patient to be suffering from persistent vomiting, typically "coffee-ground" in character. The pulse-rate was 108 and the temperature was $98 \cdot 6^{\circ} \mathrm{F}$. There was no abdominal pain or distension. The uterus was well contracted and the lochia were normal. During the day very little food or water was retained. 'By the evening the pulse-rate had risen to 120 with a normal temperature. A boric vaginal douche was given. On August 7th the vomiting still continued. Sanatogen in a small quantity of water was given at frequent intervals and at times was retained. During the day there was slight pyrexia, the temperature being $99^{\circ}$ in the morning and $99 \cdot 2^{\circ}$ in the evening. The pulse-rate was still rapid, getting up to 130 by night. The lochia remained sweet and the perineal tear appeared to be healthy. A boric vaginal douche was given once. No sleep having been obtained since the delivery a third of a grain of morphine with atropine was injected hypodermically at 10 P.M. On the 8 th the condition of affairs remained much as on the previous day. The body temperature registered $99 \cdot 6^{\circ}$ at mid-day but by the evening it had fallen to normal. The bowels, which had not acted since the confinement, were slightly moved after a simple enema. The pulse-rate was aboat 140 all the day. On the 9 th the patient when seen at 10 A.M. appeared to be markedly jaundiced; she was restless and semi-conscious. The vomiting, which still continued, was not quite so frequent though it remained " coffee ground " in character. On being informed by the nurse that much difficulty had been experienced during the night in keeping the patient's hands away from the vagina an examination of the perineum was made, showing that two or three of the sutures had been forcibly torn through the tissues The remaining stitches were removed and the parts were cleansed with a boric douche. The liver dulness on percussion appeared to be normal. A catheter specimen of the urine was obtained and on examination it was found to be albuminous and to contain leucin and tyrosin; there was no sugar present; it was deeply bile-stained. Constipation being still persistent one grain of subchloride of mercury was ordered to be given every four hours durin the following day. The pulse-rate remained at from 120 to 140 , whilst the temperature on this date was normal. On the 10th the semi-conscious condition noted on the previous day had given place to marked delirium. The bowels had acted well and vomiting had been much less frequent. During the day Dr. W. H. Maxwell Telling kindly saw the patient with me and confirmed my view of the case probably being an example of acute yellow atrophy. $\mathrm{H}^{2}$ also examined some of the urine of this date under the microscope and found leucin and tyrosin present. The liver dulness was found to extend in the mammary line from the sixth interspace to about half an inch above the costal margin. The pulse-rate remained high. Owing to the delirium very litt:e food was taken during the day; rectal saline injections were given a trial but were not retained. Urine was voided unconsciously in the bed. On the 11th the general condition of the patient appeared to be much better; there was a cessation of the delirium and of the vomiting. Food-e.g., plasmon and sanatogen-was taken well, also plenty of water. The bowels acted freely. The temperature rose to $100^{\circ}$, probably clue to a sapræmia from the perineal wound which was not looking very healthy. The liver dulness extended from the sixth inter. space to fully one and a half inches above the costal margin. On the 12th the patient had almost regained ber usual mental faculties though the liver dulness was still further diminished-not extending beyond two inches above the costal margin in the mammary line. The jaundice was less apparent though the urine was still markedly bilious. During the day an erythema, very similar to morbilli, was observed spreading from the buttocks over the trunk, the face, and the limbs. Whether this was due to the sapræmia, which judging by the pyrexia $\left(101^{\circ}\right)$ and the clean healthy appearance of the parts was not very marked or to the liver atrophy I am unable to determine. On the 14th the erythema, which on the 13th was universal, was fading. Only about one and a half inches of deep liver dulness was to be detected. The pulse-rate was 100 and the temperature was $99 \cdot 6^{\circ}$. Examination of the urine on this date showed leucin and tyrosin to be still present, as well as albumin, but no sugar. From August 15th the liver dulness rapidly increased so that by the 20th it was almost normal and the general recovery of the patient was in every way satisfactory, constipation, which was very obstinate, only being complained of. The jaundice passed off slowly and even a month later the conjunctive were distinctly icteric. At no time during the illness could the spleen be felt.

Rolleston, in "Diseases of the Liver," states that "chloroform narcosis has in most exceptional instances been followed by acute yellow atrophy." Was this case an example? Leeds.

\section{A CASE OF FRACTURE OF THE STERNUM.}

\section{By J. Finlay Alexander, M.A., M.D. Cantab.}

A FARM labourer, aged 60 years, fell off a cartload of sheaves on to the ground. The height from which he fell was probably about eight feet. He struck his head and was "stunned" for a few minutes; when he recovered consciousness he drove in the cart to the farm, stabled the horse, and then walked home a distance of one and a quarter miles. On arriving there be at once went to bed and remained lying down for three days because his chest "felt stiff when he moved." On the evening of the third day he got up, dressed himself, and walked abou's half a mile to see me. He complained of some "stiffness of the chest" and assured me that there was no swelling and "nothing to be seen." However, on making him take off his shirt there was to be seen an enormous bruise which covered nearly the whole of the front of the thorax and a ridge crossing the chest transversely at the level of the second intercostal space. There had obviously been a transverse fracture of the sternum just above the level of the attachment of the third pair of costal cartilages, and the ridge was caused by the slipping upwards and forwards of the lower fragment of the sternum, with the attached third pair of ribs, on to the upper fragment. The third rib on the right side was also fractured close to its junction with the costal cartilage. On making the patient lie down on a flat couch, without a pillow under his head, the displacement was easily reduced but returned at once when he got up. He was sent home and told to lie on a hard mattress flat on his back, and while in this position, with the displacement reduced, I firmly strapped the chest. This at once relieved all pain and within three weeks the fracture had united firmly in a good position without the formation of much callus.

The case is interesting, for, apart from the actual injury, there were no symptoms; there was never any cough or hæmoptysis, and when the man first came to see me he conld walk quickly without any shortness of breath. Alsc, the fracture is very rare. Except when it accompanies acute 
bending of the spinal column-as, for instance, in a fall from a height-or occurs with severe crushing of the whole thorax-as when the patient is run over-it is, according to Holmes's "System of Surgery," most frequently caused by a fall on to the top of the head driving the chin forcibly against the sternum; and $I$ believe that this did happen in the case under consideration, for according to the patient's own account he, as it were, dived from the cart on to the ground; and examination showed a bruise and cut on the back of the head just above the occiput. The junction between the first and second portions of the sternum is generally at the level of the second costal cartilage, so that this cartilage articulates with both the gladiolus and manubrium. But in the case just described the separation was at the level of the second interspace, so that the second pair of costal cartilages were completely attached to the top fragment and the third pair to the lower fragment. Obviously the separation did not occur at the line of union of the first and second pieces of the sternum unless this was unusually low. Professor von Reidinger and Dr. H. Kümmell, in von Bergmann's "System of Surgery," state that even when there is a synchondrosis the separation does not occur through the line of union, but the whole synchondrosis remains attached either to the manubrium or to the gladiolus, so that the injury is a true fracture and not a dislocation. This case supports their piew.

Lastingham, Yorks.

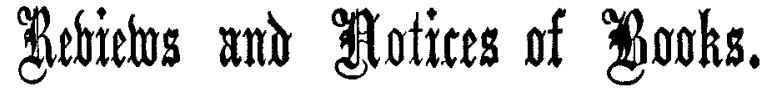

The Medioal Diseases of Infancy and Childhood. (Lippincott's New Medical Series.) By Alfred Cleveland CotTon, A.M., M.D. London and Philadelphia : J. B. Lippincott Company. 1906. Pp. 670. Price 158.

IN his work on the diseases of childhood and infancy Dr. Cotton has preserved a very happy equilibrium between the claims of nursery hygiene with its corollary the prophylaxis of disease and those of the treatment and description of morbid symptoms. There can be little doubt that the future of prediatric practice lies rather in the direction of prevention than in that of cure and if Dr. Cotton has not exactly anticipated the inevitable trend in this direction to the exclusion of some of the older branches of medicine he shows himself at least well abreast of modern developments which are rapidly conducing to this end.

The first six chapters will be found to contain a very fill account of the anatomy, physiology, and hygiene of the developing child-subjects which form a substantial basis for the proper understanding of preventive treatment. The completeness and accuracy of these chapters are indisputable and no fault can suggest itself to the most hypercritical reader unless, possibly, it be that the latter may be left with a sort of uncomfortable after-taste that the author regards the development of organs, both in their anatomical and functional relationships, from a somewhat teleological standpoint; that is to say, if we read these chapters aright, he leaves us rather to conclude that organs grow and develop according to some pre-determined design rather than that their efficiency and evolution depend on adaptation to the conditions of the environment-in other words, to the sort of use or education to which they are exposed during infancy and the early days of childhood. This fault, if fault it be, is particularly noticeable in the anthor's description of the growth of the stomach, the intestines, the heart, and the lungs, organs which are peculiarly dependent for their functional and morphological exfoliation on the sort of work which they are called upon to perform. These organs do not develop, even in relatively normal individuals, in obedience to teleological design or to text.book scales or tables, although doubtless their ultimate potentialities for work and their limits of efficiency do depend on factors which are independent of the environment.
The next few chapters, six in number to be precise, are devoted to the subject of infant feeding and these chapters give a very full account, and at the same time a very level-headed account, of the most recent development in the so-called American or percentage methods of feeding. Speaking of the recent and rapid advance in our knowledge and understanding of the art of infant feeding, the author maintains that from no quarter of the world has there been drawn more valuable practical knowledge than from that brilliant coterie of Americans, which includes the names of Leeds, Chittenden, Babcock, Harrington, Leffmann and Beam, Jacobi, Rotch, Holt, Starr, Meigs, Chapin, Van Slyke, Russell, Hart, Richmond, and the Adriences. The work of these men is most ably summarised and, indeed, on occasion criticised in these six chapters, and after weighing the advantages and disadvantages of the respective methods which are advocated by these authors the writer concludes that whatever method is adopted there is one essential that must never be lost sight of, and this is that to secure approximate accuracy-itself a most important factor-a predetermination of the gross constituents of the milk itself must be secured. For the home modification of milk, the method which is most generally applicable, the author insists that the mother or the nurse must be instructed in regard to all details and supplied with the necessary utensils; the latter include a good ice-box, two syphons, a steriliser or pasteuriser, a thermometer, a dozen graduated feeding-tubes, bottle brushes, absorbent cotton, straining gauze, non-ahsorbent cotton for stoppers, a mixing pitcher, an eight-ounce graduated glass funnel, a tall cup for warming the bottle, six black rubber nipples, bicarbonate of sodium, and boric acid-a list of desiderata which would probably inspire considerable awe in the minds of the majority of English mothers, but which, none the less, are absolutely essential for the proper carrying out of the best method of artificial feeding. In contradistinction to many American authors on infant feeding Dr. Cotton admits the merits of dextrinised gruels as adjuncts to an otherwise exclusive diet of modified milk.

Considerable attention is given in these pages to the evolution of gastric digestion in the developing infant. Our knowledge on this subject, as is explained on page 74, has been very considerably extended by the studies of Van Slyke and Hart on the production of cottage and Cheddar cheeses and on the chemical behaviour of caseins in the presence of acids, rennet, and pepsin. The author borrows very largely from an article by Dr. T. S. Southworth which appeared in the Medical Record of March 4th, 1905, to show how a knowledge of the chemical processes, which can be repeated in the test-tube, may explain the gradual development of gastric digestion in the infant. "It is," to quote the article referred to, "one of the most remarkable things in nature that milk, which itself maintains practically the same composition throughout lactation, is changed by the action upon it of the developing gastric secretion into forms and compounds which require at first moderate and later more extended gastric digestion, by which means the stomach is progressively called upon to perform more and more work until it is sufficiently developed to begin its subsistence upon the types of food consumed by the adult of its species." This principle, which is so interestingly displayed by the natural process of feeding, is the type to which Dr. Cotton very closely adheres in the artificial methods of feeding which he recommends. Indeed, as he maintains, it is by the study of the digestive processes at different periods of development that the problem of physiological feeding must be solved, and it is clearly to Dr. H. D. Chapin, the pioneer of this principle in feeding, that the author owes many of his most valuable suggestions. The later chapters of this work, which are concerned chiefly with 